\section{BMJ Open Respiratory Research}

\title{
Feasibility and acceptability of introducing advance care planning on a thoracic medicine inpatient ward: an exploratory mixed method study
}

\author{
Nina Elisabeth Hjorth (D) ,,2 Margrethe Aase Schaufel (D) ,3,4 \\ Katrin Ruth Sigurdardottir (D) , 4,5 Dagny R Faksvåg Haugen (D) 2,4
}

To cite: Hjorth NE, Schaufel MA, Sigurdardottir KR, et al. Feasibility and acceptability of introducing advance care planning on a thoracic medicine inpatient ward: an exploratory mixed method study. BMJ Open Resp Res 2020;7:e000485. doi:10.1136/ bmjresp-2019-000485

Received 29 August 2019 Revised 14 January 2020 Accepted 23 January 2020

Check for updates

(C) Author(s) (or their employer(s)) 2020. Re-use permitted under CC BY-NC. No commercial re-use. See rights and permissions. Published by BMJ.

${ }^{1}$ Department of Anaesthesia and Surgical Services, Specialist Palliative Care Team, Haukeland University Hospital, Bergen, Norway ${ }^{2}$ Department of Clinical Medicine K1, University of Bergen, Bergen, Norway ${ }^{3}$ Department of Thoracic Medicine, Haukeland University Hospital, Bergen, Norway

${ }^{4}$ Regional Centre of Excellence for Palliative Care, Western Norway, Haukeland University Hospital, Bergen, Norway ${ }^{5}$ Sunniva Centre for Palliative Care, Haraldsplass Deaconess Hospital, Bergen, Norway

Correspondence to Dr Nina Elisabeth Hjorth; nina.elisabeth.hjorth@helsebergen.no

\section{ABSTRACT}

Background and aims Advance care planning (ACP) is communication about wishes and preferences for endof-life care. ACP is not routinely used in any Norwegian hospitals. We performed a pilot study (2014-2017) introducing ACP on a thoracic medicine ward in Norway. The aims of this study were to explore which topics patients discussed during ACP conversations and to assess how patients, relatives and clinicians experienced the acceptability and feasibility of performing ACP.

Methods Conversations were led by a study nurse or physician using a semistructured guide, encouraging patients to talk freely. Each conversation was summarised in a report in the patient's medical record. At the end of the pilot period, clinicians discussed their experiences in focus group interviews. Reports and transcribed interviews were analysed using systematic text condensation.

Results Fifty-one patients participated in ACP conversations (41-86 years; 9 COPD, 41 lung cancer, 1 lung fibrosis; 11 women); 18 were accompanied by a relative. Four themes emerged: (1) disturbing symptoms, (2) existential topics, (3) care planning and (4) important relationships. All participants appreciated the conversations. Clinicians ( 1 physician and 7 nurses) participated in two focus group interviews. Reports from ACP conversations revealed patient values previously unknown to clinicians; important information was passed on to primary care. Fearing they would deprive patients of hope, clinicians acted as gatekeepers for recruitment. Although they reported barriers during recruitment, many clinicians saw ACP as pertinent and called for time and skills to integrate it into their daily clinical practice. Conclusions Patients, relatives and clinicians showed a positive attitude towards ACP. Focusing on present and future symptom control may be an acceptable way to introduce ACP. Important aspects for implementing ACP in this patient group are management support, education, training, feasible routines and allocated time to perform the conversations.

\section{INTRODUCTION}

Advance care planning (ACP) is a process of conversations enabling individuals to define goals and preferences for future medical

\section{Key messages}

To explore feasibility and acceptability of introducing advance care planning (ACP) in a Norwegian hospital.

- Patients and clinicians perceived ACP conversations as pertinent, though a future implementation is not without challenges.

In the conversations, patients revealed four main topics important for their future situation.

treatment and care; to discuss these goals and preferences with family and healthcare providers across the physical, psychological, social and spiritual domains; and to record these preferences if appropriate. ${ }^{1}$ ACP encourages individuals to identify a personal representative and to regularly review any preferences, so that their wishes can be taken into account should they, at some point, be unable to make their own decision. ${ }^{2}$

Patients with advanced pulmonary disease (chronic obstructive pulmonary disease (COPD), lung cancer and lung fibrosis) often suffer from a high symptom burden and severe prognosis. ${ }^{3-5}$ Studies show that this patient group may benefit from ACP, but also that it is often not offered. ${ }^{6-8}$ Good decisionmaking processes are increasingly warranted in clinical medicine with the heightened focus on patient autonomy, but the need for and openness toward ACP might vary between cultures and different diagnostic groups. ${ }^{36910}$ In Norway, ACP is still in its infancy and not used routinely, and there is a lack of research addressing how ACP can support patients with advanced pulmonary disease. ${ }^{31-15}$

The aim of the present research was to improve our understanding of how ACP could ideally be approached in Norway, with particular attention to the needs of patients with advanced pulmonary disease. The objectives 
of the present study were to pilot a simple ACP guide in conversations with inpatients on a thoracic medicine ward, to explore which topics patients brought up during the conversations, and to assess how patients, relatives and staff experienced and evaluated the contents and the feasibility of performing ACP.

\section{MATERIALS AND METHODS}

The study was conducted in three phases: development of a conversation guide, conducting patient conversations and conducting focus groups to determine ward staff receptivity to ACP.

\section{Study setting}

The study took place during the period 2014-2017 on the inpatient wards of the Department of Thoracic Medicine at Haukeland University Hospital, Bergen, Norway. This department has about 20000 outpatient consultations and 3000 inpatient admissions per year, mostly acute admissions, with COPD, lung cancer and lung infections as dominant diagnoses. During the study period, $54.3 \%$ of inpatients were male, and COPD and lung cancer diagnoses were about equal in numbers.

\section{Participants}

Inclusion criteria for participating patients were being diagnosed with advanced, non-curable pulmonary disease (eg, inoperable lung cancer, COPD or pulmonary fibrosis) and being inpatients at the department of thoracic medicine. Clinicians participating in focus group interviews should work as nurses or physicians at the department of thoracic medicine during the study period. For all, participation required age over 18 years, ability to communicate orally in Norwegian, and ability and willingness to provide written informed consent. Exclusion criteria were severe cognitive impairment and other circumstances (eg, anxiety, impaired hearing and reduced functional ability) representing a severe challenge to reasoning and/or communication. To describe the study population, parts of the European Association for Palliative Care (EAPC) basic dataset, including Edmonton Symptom Assessment System Revised, and 'List of Educational Levels' from Statistics Norway were used (table 1)..$^{16-18}$

\section{Procedure}

The first phase of this project was to ask patients in the target group about their views on ACP. ${ }^{19}$ Based on the results from this focus group study and input from international literature, we developed a simple, semistructured guide for ACP (box 1). ${ }^{20}$

In the second phase, we used the guide (box 1) as a basis for ACP conversations with patients on a thoracic medicine inpatient ward. We aimed to include 50 patients in the pilot study. Initially, recruitment was conducted by clinicians on the ward and, later, due to problems reaching our recruitment goal, by a study nurse. Eligible patients were informed about the study and were asked if they were interested in having an ACP conversation.

\begin{tabular}{|c|c|c|c|c|c|}
\hline Gender & & Age & & Level of education & \\
\hline \multirow[t]{2}{*}{ Female } & 11 & Average & 69.4 & Lower secondary education & 1 \\
\hline & & & & Upper secondary education, basic & 9 \\
\hline \multirow[t]{5}{*}{ Male } & 40 & Median & 70 & Upper secondary education, final & 16 \\
\hline & & & & Postsecondary, non-tertiary education & 2 \\
\hline & & Range & $41-86$ & Tertiary education, undergraduate level & 9 \\
\hline & & & & Tertiary education, graduate level & 3 \\
\hline & & & & Unspecified education & 11 \\
\hline Primary diagnosis & & Additional diagnosis & & & \\
\hline \multirow[t]{2}{*}{ COPD } & 9 & Abdominal aortic aneurysm & 1 & & \\
\hline & & Anxiety/depression/ psychiatric & 4 & & \\
\hline \multirow[t]{2}{*}{ Lung cancer } & 41 & Cancer, other than principal & 8 & & \\
\hline & & COPD/emphysema & 18 & & \\
\hline \multirow[t]{6}{*}{ Lung fibrosis } & 1 & Heart disease & 24 & & \\
\hline & & Hormonal disease & 4 & & \\
\hline & & Infection & 9 & & \\
\hline & & Respiratory failure & 9 & & \\
\hline & & Thrombotic events & 5 & & \\
\hline & & Other & 9 & & \\
\hline
\end{tabular}

COPD, chronic obstructive pulmonary disease. 


\section{Box 1 Semistructured guide for advance care planning (ACP) conversations in the pilot study}

\section{Part 1: planning the conversation}

1. Does the patient wish an ACP conversation? (includes information about ACP and about the project)

2. Which themes are (currently) relevant?

3. Who is going to attend?

4. Time and place for the conversation.

5. Is there a need for an interpreter?

\section{Part 2: possible themes for the ACP conversation (a list to choose from)}

1. Information about the disease: past, current and future. Does the patient have special needs or reservations concerning information?

2. The patient's expectations for the future based on past and present experiences.

3. What gives the patient strength and resilience? Key words: coping strategies, existential and/or spiritual attitudes, values and beliefs.

\section{Does the patient wish...}

4. ...to appoint a proxy?

5. ...help with legal or economic challenges?

6. ...to document specific wishes concerning the last phase of life (eg, do not attempt resuscitation/respirator) in his or her medical record?

\section{Evaluation of the ACP conversation:}

1. What does the patient—and relative(s), if applicable —-think about participating in this conversation?

The availability of the study nurse, usually limited to 1 or 2 days a week, regulated both the inclusion of new participants and conversations completed. Patients agreeing to participate took part in the planning of the conversation as outlined in box 1. An appointment was scheduled on the same day or one of the next days.

The conversations took place in the patient's room or in a separate room on the ward. After having received some practical training initially from the first author, the study nurse led most of the conversations (42); only 9 conversations were facilitated by the first author (8) or the attending physician (1). The participating patients were encouraged to talk freely about matters of importance for their present and future situations (box 1). If relatives attended, they participated actively in the ACP conversations and their comments were included in the reports. Before closing, participants were asked how they had experienced the conversation. A summary of the conversation was documented as a report in the patient's medical record and was also anonymised and stored on a secure research server.

After the last ACP conversation had been held, phase III started. Clinicians working on the ward during the pilot period had been informed about the study orally and in writing and had been invited to participate in phase II. In phase III, they were invited to participate in focus group interviews exploring their ideas about and experiences with the ACP pilot study. ${ }^{21}{ }^{22}$ Two of the authors (NEH as facilitator and MAS as secretary) facilitated the focus groups. Most of the participants knew the facilitators as present or former colleagues on the ward, NEH being a consultant in the palliative care team and MAS being a consultant at the department. Two focus group interviews took place, lasting 35 and $40 \mathrm{~min}$, respectively. The interviews were recorded and transcribed verbatim by a secretary.

\section{Data analysis}

Data analysis was by mixed methods: quantitative data, such as recruitment and activities, were analysed using descriptive statistics, while qualitative methods, in terms of systematic text condensation, were used when analysing reports of ACP conversations and the transcribed focus group interviews. Qualitative analysis was performed in collaboration between the authors, with the analysis proceeding through the following stages: (1) reading all the material to obtain an overall impression, bracketing preconceptions; (2) identifying units of meaning representing different elements and coding for these; (3) condensing and abstracting the meaning within each of the coded groups; and (4) summarising and generalising description and concept categories. ${ }^{23}$

\section{Patient and public involvement}

Before making the ACP guide, patients in the target group participated in focus group interviews, giving their opinion on ACP: if this should be offered, with whom and when they would want such conversations, and what topics they found relevant. ${ }^{19}$

\section{RESULTS}

\section{Participants in ACP conversations}

One hundred and eighteen patients were invited to participate in the ACP conversations; 51 finally participated. Sixty-five patients declined participation for reasons spanning from disinterest to bad timing. Twenty-nine of the non-participating patients $(45 \%, 25 \%$ of all approached patients) gave reasons indicating that they were positive but that the timing was bad for practical reasons or that their time was already occupied, or that they were too ill. Thirty-six patients $(55 \%$ of non-participating patients, $31 \%$ of all) declined for reasons such as 'too demanding' 


\section{Eligible patients $\mathrm{n}=118$}

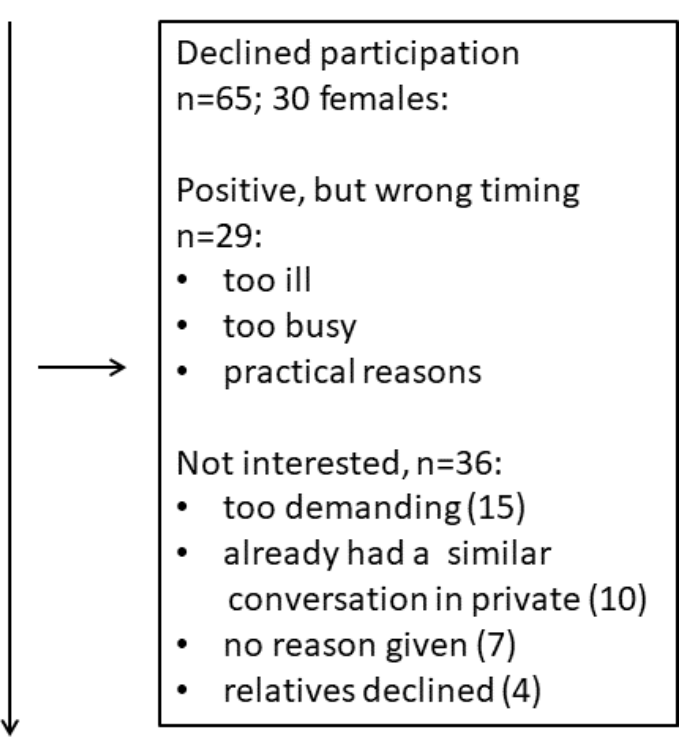

\section{Agreed to participation $\mathrm{n}=53$}

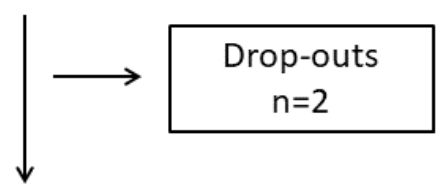

Participated in the study $\mathrm{n}=51 ; 11$ females;

\section{1 lung cancer, 9 COPD, 1 lung fibrosis}

Figure 1 Overview of the recruitment process for advance care planning conversations. COPD, chronic obstructive pulmonary disease.

(15 patients) or 'had already had a similar conversation in private' (10 patients, $15 \%)$. Seven patients gave no reason for refraining from participation. Four patients were initially positive but declined after consulting a relative. Figure 1 gives an overview of recruitment. Eighteen conversations included a close relative. Reasons for not bringing a relative spanned from lack of closeness to wanting to protect them from a tough conversation, but most often, it was a matter of logistics. The conversations lasted 30-60 min, sometimes longer. Characteristics of the participating patients are presented in table 1 and in figure 2.

\section{Participants in focus groups}

One male physician and seven nurses (all women), with a mean age of 39 years (range 25-58), participated in focus group interviews. They had been working at the department from 1.5 to 29 years (mean 9.4, median 4.5). Two were specialist nurses and two were leaders. For logistic reasons, the participants were divided into two groups.

\section{Contents}

The themes from the guide appeared relevant, as displayed in table 2.

\section{Topics of the ACP conversations}

From the qualitative analysis of the conversation summaries, four main categories emerged: (1) troublesome symptoms and alleviation of these; (2) existential themes such as coping, resilience and death; (3) planning of future treatment and care; and (4) important relations.

\section{Troublesome symptoms and alleviation of these}

Most patients were troubled by several symptoms related to exhaustion and loss of functions, with dyspnoea and tiredness as the most frequent (figure 2). Many of the participants feared insufficient symptom relief in the last phase of life, and this fear could exceed their fear of death itself. Many requested better alleviation.

Anxiety was triggered by changes, as by other symptoms, especially dyspnoea, and by the way information, examinations and treatments were introduced and given. How symptoms were perceived was often related to the interpretation of their importance, illustrated by a patient questioning his cancer treatment because he had overwhelming pain. Some patients experienced pain as an invading scourge reducing their quality of life, taking away their feeling of control and stealing their courage. Even though patients were grateful for the help they received, several problematised the dependence on others to obtain pain relief, stressing the importance of being believed and respected, and getting medication at the right moment. Relatives also voiced how difficult it could be to support a patient in agony.

\section{Existential themes}

Most patients described their own family as the basis for their existence. Thus, places for family gatheringstheir house, cabin, garden, or holiday trips-became important existential factors and sources of strength. Through their stories about the past, they described sorrow over lost functions, lost dignity, lost relations and lost future. Life would be shorter than expected, and although this was a sensitive theme, several raised it. Earlier experiences with illness and disease, either as a relative or as a patient, mostly increased their present resilience.

While some participants were open about their religious beliefs, others expressed that this area was too private to share. Many presented indifference to religious questions while at the same time admitting a belief in something superior, such as a Christian childhood faith. Some expressed a negative attitude towards religiousness. Acknowledging the approaching death, many chose 


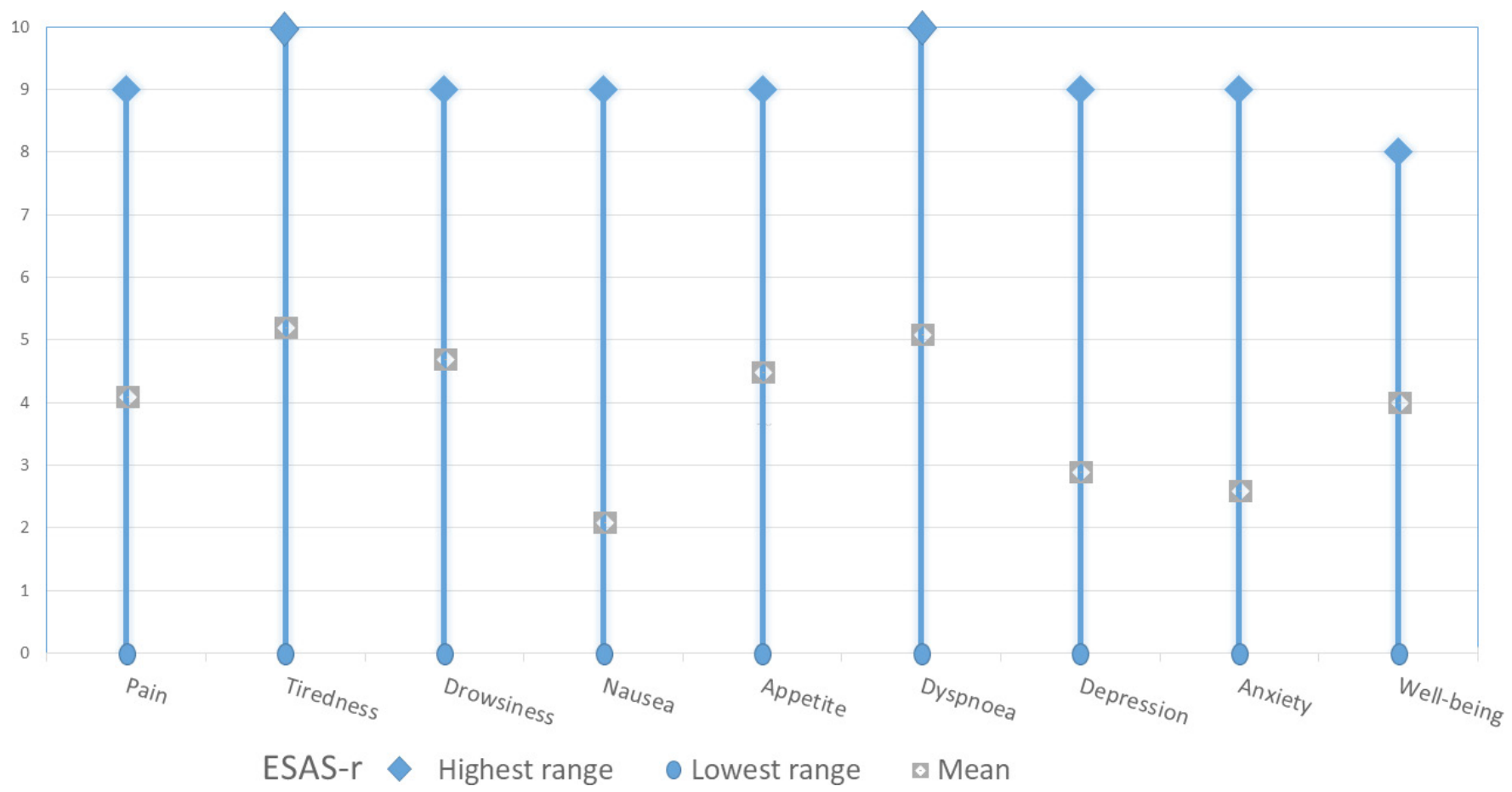

Figure 2 ESAS-r: participating patients' expression of symptoms rated by Numerical Rating Scale. ESAS-r, Edmonton Symptom Assessment System Revised.

to focus on life at present, taking one day at a time, often called 'positive thinking'.

\section{Planning for the last phase of life}

While many preferred positive thinking and postponed planning for the future, others talked about reorganising their private economy and transferring their responsibilities. Some had written a will, and some had even planned their funeral. Some participants described specific wishes concerning end-of-life care, and some had discussed this with their next of kin. While several mentioned an unwillingness to be treated purposelessly, a few demanded that clinicians should respect their choices for treatment dictated by themselves or their proxy.

Quite a few talked about 'dying with dignity', meaning being safe and certain to get help when needing it. Important for the patients' feeling of a comforting safety were the community personnel, at home or in a nursing

Table 2 Number of participants who talked about each item under possible themes for the advance care planning conversation

\begin{tabular}{|c|c|}
\hline $\begin{array}{l}\text { Themes for conversations (from } \\
\text { the guide) }\end{array}$ & $\begin{array}{l}\text { Patients who talked } \\
\text { about each theme (n) }\end{array}$ \\
\hline Information about the disease & 35 \\
\hline Expectations for the future & 49 \\
\hline Sources of strength and resilience & 40 \\
\hline Appointment of proxy & 7 \\
\hline Legal or economic challenges & 8 \\
\hline Documentation of specific wishes & 12 \\
\hline
\end{tabular}

home, necessary equipment and financial aid, the ambulatory specialist palliative care team and having open access to the local hospital.

It was important to all patients that information be given with empathy, respecting their needs, as well as limits, for receiving medical information. Several patients told about difficulties remembering information and the resulting difficulties making plans. Some patients asked for more thorough information on diagnosis, prognosis and treatment in order to make their plans.

\section{Good relationships}

Patients talked about how important it was to be supported by someone who knew and understood their situation. Many of them got this support from close family members, others through their jobs or as members of clubs or associations. It was highly valued to bring their spouse or child to consultations, and seven patients named specific proxies, all from close family. Some had a clear wish for home death and found safety in a declaration of support from their relatives.

Approaching death, patients found that disharmony in relations was especially painful. Some talked about remoteness, either as related to their personality, their family history or to the situation of having advanced disease. A few expressed grief because of loneliness and told about lacking support from their next of kin. Several patients told about a supportive staff on the ward contributing to a feeling of safety. 


\section{Evaluation of ACP conversations by patients and relatives}

Several patients expressed relief after talking about endof-life issues, while others said that the conversation had started an important process of thinking ahead. A few wanted a follow-up conversation with a psychologist or a chaplain.

All patients and relatives expressed that they appreciated the conversation, and many recommended it to be offered routinely at the department.

\section{Feasibility}

\section{Findings from focus group interviews with clinicians}

The following main themes came up during the focus groups with clinicians: (1) benefits of ACP and (2) challenges concerning feasibility, divided into two subgroups: (1) barriers against implementation of ACP and (2) organisational aspects. Clinicians reading the ACP reports found new and valuable information that sometimes was passed on to the primary care services. Some suggested ACP as an optional part of discharge planning. Many experienced barriers against ACP, and implementation was regarded challenging in several ways: appropriate patient selection and timing of the conversation were regarded as crucial factors for an acceptable practice. To avoid deprivation of hope, clinicians regarded respect for the patient's boundaries concerning transparency and communication as highly important. They called for time, applicable routines and skills to integrate ACP into their daily practice. The findings are presented in table 3 .

\section{DISCUSSION}

Patients talked about principal topics when planning for their last phase of life. In addition to symptoms, future alleviation of these and care planning, they discussed identity, beliefs and important relations. Although questioning the organisation of ACP and having barriers for its uptake, clinicians saw the need for ACP conversations and called for management support, requesting education, time and a feasible arrangement for ACP. We discuss these findings further, including the strengths and limitations of this study.

\section{Content: ACP conversations}

This was the first time systematic ACP conversations were performed on a thoracic medicine ward in Norway. Only $15 \%$ of the eligible non-participating patients had previously participated in such conversations. This underlines the need for a better organisation of ACP in Norway.

Hospitals may not seem the obvious place for ACP, but an admission may trigger the need for it. ${ }^{20}{ }^{24}$ We know that breaking points during the disease trajectory, such as a change in therapy, are triggers for ACP conversations. ${ }^{19} 20$ In this study, a rather large number of the participating patients with cancer $(27 / 41)$ did not receive anticancer therapy when joining the study. Worsening of the disease might have triggered a need for an ACP conversation. Early integration of palliative care for patients with lung cancer has been proven to be beneficial. ${ }^{26}$ ACP may be an important aspect of this approach. If clinicians avoid these conversations, an opportunity to improve the care for patients with advanced pulmonary disease will be missed. ${ }^{46}$

We practised a person-centred ACP using the guide only as a support while focusing on the patient's wishes, needs and preferences, respecting individual limits for transparency, as recommended by Waldrop and Meeker, among others. ${ }^{20} 2728$ A consequence of a person-centred focus may be that sensitive topics are avoided, with uncertainty about reasons for avoidance. However, we experienced that many patients raised rather challenging topics, indicating that the person-centred focus was both sensitive and reliable (table 2). As the reports of the conversations gave new and varied information, we conclude that our guide (box 1) may be useful in person-centred ACP conversations.

Almost all participating patients talked about troublesome symptoms, and many expressed distress related to fear for insufficient alleviation in the future. Patients needed to understand what the symptoms represented during the disease trajectory. From this observation, we derive that focusing on bothering symptoms and loss of functions, at present and in the future, may facilitate an ACP conversation. We have not found this approach described previously as a systematically used conversation technique.

While many patients found resilience when focusing on the present, some preferred to talk about their past. This gave clues about the patients' values and coping strategies, important information for future decision-making. This correlates to findings of Thoresen and Lillemoen when studying ACP conversations in nursing homes. ${ }^{14}$

The process of ACP is a multifactorial task in which knowledge about prognosis, expected care and support are important topics. In a review describing the five most important elements in end-of-life care, as judged by hospital inpatients and their relatives, effective clinical communication and shared decision-making were ranked as number one. ${ }^{29-31}$ This pilot study confirms this finding in that the described perceived lack of information, with the resulting difficulty in making plans, emphasises the need for more effective clinical communication. ${ }^{32}$ Supporting relations-in the healthcare system and especially within the family - were decisive when determining the level of care on discharge, contributing to patients' feeling of safety.

\section{Feasibility of ACP conversations}

In this study, feasibility of ACP conversations was challenging mainly because of barriers, divided into time and knowledge, and organisational aspects. According to Jabbarian et al, time barriers are partly a system error, 


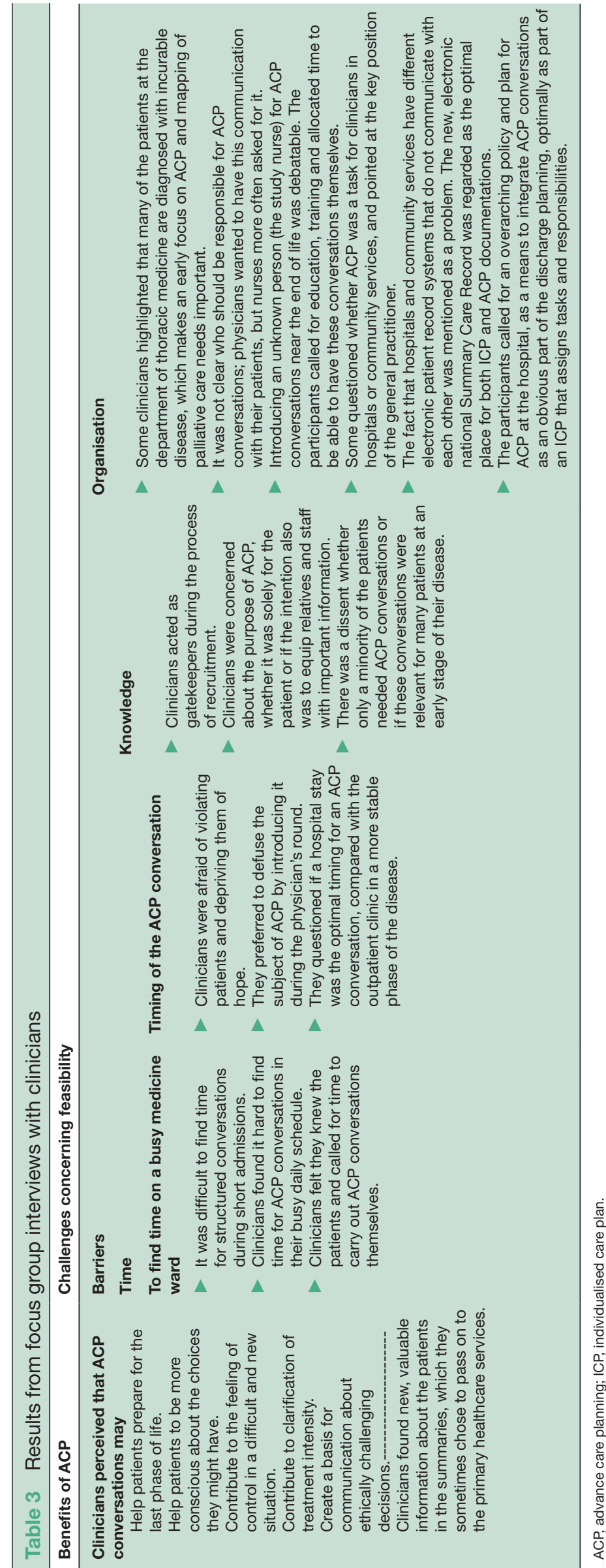


while the barrier of timing for ACP, though known universally, is more individual. ${ }^{68}$

Patient-related barriers for the uptake of ACP are known as diverse and are described in several studies. ${ }^{6} 82033$ We observed that both patients and relatives wished to protect one another from tough conversations. ${ }^{34}{ }^{35}$ When patients decline participation because of 'bad timing', it may reflect the load of sickness and logistics or, on the other hand, patient hesitation for discussing treatment preferences. ${ }^{336}$ Patients' focus on positive thinking is a known patient-related barrier for the uptake of ACP. ${ }^{33} 3738$ Additionally, we observed that patients need to be primed to conduct ACP, that time limitations often prevent clinicians from conducting ACP and that logistics of hospitalisations are also barriers (table 3) ${ }^{839}$

The literature shows that patients with COPD are especially difficult to introduce to ACP, partly because they have an unpredictable disease trajectory and partly because the importance of early introduction of ACP is poorly recognised. ${ }^{6834}$ In the present study, the number of participating patients with COPD as their principal diagnosis was only nine, which does not reflect the proportion of admissions of patients with COPD during the study period. This finding supports the low uptake of ACP in this diagnostic group and underlines the need for extra attention when inviting patients with COPD to ACP conversations. $^{62535}$

In the focus groups, a debate about organising and standardising ACP conversations and documentation of these came up as a consequence of the positive impact of the project. So, despite having barriers against ACP, clinicians perceived ACP as important, as also shown by others. ${ }^{8} 92040-43$ Starting up the pilot study with help from ward staff, we soon discovered problems for recruitment related to time and knowledge (table 3), and we introduced a study nurse. In line with the study by Friis and Førde, our study did not show a necessity of having a long-term relation with the patient before introducing ACP. $^{13}{ }^{44}$ Clinicians were uncertain about which profession should facilitate ACP conversations. International guidelines state that any member of the clinical team can do ACP as long as they have relevant communication skills and are empowered to do so. ${ }^{2445} 46$

Lacking knowledge about how ACP may strengthen patients' hope by talking about their future, clinicians acted as gatekeepers in order to protect patients against possibly tough conversations. ${ }^{34} 45$ This illustrates the importance of providing sufficient documentation and information, as well as installing engagement, to accomplish successful implementation of ACP. ${ }^{84}$

We chose to use a free text summary in the hospital's electronic medical record for documentation and not a rigid template. The EAPC white paper on ACP recommends the use of both forms of documentation: the first for documenting attitudes and values, and the latter for an easy retrieval of concrete wishes and preferences. ${ }^{2}$ Clinicians in our study suggested the documentation to be placed in a new, electronic national Summary Care
Record, possibly as part of an individual palliative care plan. ${ }^{47}$ However, this national record does not have the form or space to contain a complete ACP document. It is important to find a common Norwegian approach to these challenges concerning documentation.

\section{Strengths and limitations \\ Strengths}

Arranging focus group interviews with patients in the target group before constructing the guide and conducting this ACP pilot study allowed patients' voices to be heard and respected. The patient-centred focus contributed to increased patient autonomy. Recruited patients suffered from advanced disease; thus, our study develops knowledge about important patient-selected topics at this sensitive point in their illness trajectory. Our study sample showed variations regarding comorbidity, education, age and functional status, suggesting that our findings are transferable to other hospital settings with similar patient populations. Seventy per cent of the invited patients were positive to ACP, demonstrating that our model for integrating ACP on a thoracic medicine ward was acceptable to the majority, even though a proportion for different reasons were prevented from study participation.

\section{Limitations}

To be included in the study, patients should either be able to read the patient information sheet or understand the meaning when being informed about it and give written informed consent. This criterion might have given a risk of excluding the sickest. Using a study nurse, a stranger to the patients, could be a limitation during the recruitment process. Patients did not have the possibility to review the summaries; consequently, we do not know if they had wanted amendments. The number of participating women (11) was comparably lower than the number admitted during the study period. In retrospect, considering a rather high staff turnover causing lack of continuity on the ward, we realise that the research team did not give clinicians sufficient information during the study period. This discontinuity was also a limitation for evaluation of the project. Only one physician participated in the focus groups due to logistic reasons; thus, our findings regarding ACP evaluation may not be transferable to the medical profession. The research team knew the department and several participants well, which may have prevented negative feedback. However, the informants' critical outline of challenges regarding ACP, as well as descriptions of benefits, makes it likely their comments were delivered in honest terms.

\section{CONCLUSIONS}

Patients with advanced pulmonary disease, their relatives and clinicians found patient-centred ACP pertinent, yet a sustainable implementation seemed challenging to establish. When introducing ACP, a focus on present and 
future symptom control may facilitate the conversations. Important aspects for implementing ACP for this patient group are management support, education, training, feasible routines and allocated time.

Acknowledgements We thank the participating patients for sharing their thoughts with us and the study nurse, Øyvind I. Rød, for performing a skilled job with inclusions and conversations. We also thank our cooperating colleagues at the Department of Thoracic Medicine (Haukeland University Hospital, Bergen, Norway) for their help and support, especially the nurses Bodil Leivdal and Målfrid Årflot, and the focus groups participants. We acknowledge the professional assistance from the nurses and secretaries at the Regional Centre of Excellence for Palliative Care, Western Norway.

Contributors Conception and design: NEH, MAS, KRS and DRFH. Data collection: NEH and MAS. Data analysis and interpretation: NEH, MAS and DRFH. Drafting of the manuscript: NEH. Revision of the manuscript: NEH, MAS, KRS and DRFH. Final approval of the version to be published: NEH, MAS, KRS and DRFH.

Funding NEH was supported by a grant from The Sunniva Foundation, Haraldsplass Deaconess Hospital, Bergen, Norway.

Competing interests None declared.

Patient consent for publication Not required.

Ethics approval This study was approved by the Regional Committee for Medical and Health Research Ethics, Western Norway (2014/1054-1 REK West). Written informed consent was obtained from all participants.

Provenance and peer review Not commissioned; externally peer reviewed.

Data availability statement Deidentified participant data are available upon reasonable request from the corresponding author.

Open access This is an open access article distributed in accordance with the Creative Commons Attribution Non Commercial (CC BY-NC 4.0) license, which permits others to distribute, remix, adapt, build upon this work non-commercially, and license their derivative works on different terms, provided the original work is properly cited, appropriate credit is given, any changes made indicated, and the use is non-commercial. See: http://creativecommons.org/licenses/by-nc/4.0/.

ORCID iDs

Nina Elisabeth Hjorth http://orcid.org/0000-0003-1306-5439

Margrethe Aase Schaufel http://orcid.org/0000-0001-9273-2345

Katrin Ruth Sigurdardottir http://orcid.org/0000-0001-8192-7470

Dagny R Faksvåg Haugen http://orcid.org/0000-0002-8592-4995

\section{REFERENCES}

1 Sudore RL, Lum HD, You JJ, et al. Defining advance care planning for adults: a consensus definition from a multidisciplinary Delphi panel. J Pain Symptom Manage 2017;53:821-32.

2 Rietjens JAC, Sudore RL, Connolly M, et al. Definition and recommendations for advance care planning: an international consensus supported by the European Association for Palliative Care. Lancet Oncol 2017;18:e543-51.

3 Vermylen JH, Szmuilowicz E, Kalhan R. Palliative care in COPD: an unmet area for quality improvement. Int $J$ Chron Obstruct Pulmon Dis 2015;10:1543-51.

4 Rocker GM, Cook D. 'INSPIRED' approaches to better care for patients with advanced COPD. Clin Invest Med 2013;36:114-20.

5 Gysels $\mathrm{MH}$, Higginson IJ. The lived experience of breathlessness and its implications for care: a qualitative comparison in cancer, COPD, heart failure and MND. BMC Palliat Care 2011;10:15.

6 Patel K, Janssen DJA, Curtis JR. Advance care planning in COPD. Respirology 2012;17:72-8.

7 Siouta N, van Beek K, Preston N, et al. Towards integration of palliative care in patients with chronic heart failure and chronic obstructive pulmonary disease: a systematic literature review of European guidelines and pathways. BMC Palliat Care 2016;15:18.

8 Jabbarian LJ, Zwakman M, van der Heide A, et al. Advance care planning for patients with chronic respiratory diseases: a systematic review of preferences and practices. Thorax 2018;73:222-30.

9 Andreassen P, Skorstengaard M, Neergaard M, et al. "Vi må tage det som det kommer": erfaringer med Advance Care Planning-samtaler i Danmark [Experiences with Advance Care Planning in Denmark]. Omsorg 2014;2:9-13.

10 Be open, be ready, be heard. advance care planning, Austin health website, Australia, 2018. Available: http://advancecareplanning.org. au/ [Accessed 02 Jan 2020].
11 Beslutningsprosesser for begrensning av livsforlengende behandling [Decision making Processes for Limitation of Life-Sustaining Treatment]. Norwegian Directorate of Health, 2013. Available: https:// www.helsedirektoratet.no/veiledere/beslutningsprosesser-vedbegrensning-av-livsforlengende-behandling [Accessed 02 Jan 2020].

12 Aasmul I, Husebo BS, Flo E. Description of an advance care planning intervention in nursing homes: outcomes of the process evaluation. BMC Geriatr 2018;18:26.

13 Friis P, Førde R. Forhåndssamtaler med geriatriske pasienter. [Advance care planning discussions with geriatric patients]. Tidsskr Nor Legeforen 2015;135:233-5.

14 Thoresen L, Lillemoen L. "I just think that we should be informed" a qualitative study of family involvement in advance care planning in nursing homes. BMC Med Ethics 2016;17:72.

15 Fosse A, Schaufel MA, Ruths S, et al. End-of-life expectations and experiences among nursing home patients and their relatives - a synthesis of qualitative studies. Patient Educ Couns 2014;97:3-9.

16 Sigurdardottir KR, Kaasa S, Rosland JH, et al. The European Association for Palliative Care basic dataset to describe a palliative care cancer population: Results from an international Delphi process. Palliat Med 2014;28:463-73.

17 Watanabe SM, Nekolaichuk CL, Beaumont C. The Edmonton symptom assessment system, a proposed tool for distress screening in cancer patients: development and refinement. Psychooncology 2012;21:977-85.

18 Classification of education (NUS). Statistics Norway (SSB), 2018. Available: https://www.ssb.no/klass/klassifikasjoner/36 [Accessed 30 Dec 2019].

19 Hjorth NE, Haugen DF, Schaufel MA. Advance care planning in lifethreatening pulmonary disease: a focus group study. ERJ Open Res 2018;4:00101-2017.

20 Thomas K, Lobo B, Detering K. Advance care planning in end of life care. 2nd edn. United Kingdom: Oxford University Press, 2018: 301.

21 Malterud K. Kvalitative metoder i medisinsk forskning. En innføring. [Qualitative methods in medical research. An introduction.] Universitetsforlaget, Oslo, Norway, 2011.

22 Malterud K. Fokusgrupper som forskningsmetode for medisin og helsefag. [Focus groups as a research method for medicine and applied health sciences.] Universitetsforlaget, Os/o, Norway, 2012.

23 Malterud K. Systematic text condensation: a strategy for qualitative analysis. Scand J Public Health 2012;40:795-805.

24 Ólafsdóttir KL, Jónsdóttir H, Fridriksdóttir N, et al. Integrating nursefacilitated advance care planning for patients newly diagnosed with advanced lung cancer. Int J Palliat Nurs 2018;24:170-7.

25 Duenk RG, Heijdra Y, Verhagen SC, et al. PROLONG: a cluster controlled trial to examine identification of patients with COPD with poor prognosis and implementation of proactive palliative care. BMC Pulm Med 2014:14:54.

26 Temel JS, Greer JA, Muzikansky A, et al. Early palliative care for patients with metastatic non-small-cell lung cancer. N Engl J Med 2010;363:733-42.

27 Waldrop DP, Meeker MA. Communication and advanced care planning in palliative and end-of-life care. Nurs Outlook 2012;60:365-9.

28 Sævareid TJL, Førde R, Thoresen L, et al. Significance of advance care planning in nursing homes: views from patients with cognitive impairment, their next of kin, health personnel, and managers. Clin Interv Aging 2019;14:997-1005.

29 Virdun C, Luckett T, Lorenz K, et al. Dying in the hospital setting: a meta-synthesis identifying the elements of end-of-life care that patients and their families describe as being important. Palliat Med 2017;31:587-601.

30 Brinkman-Stoppelenburg A, Rietjens JAC, van der Heide A. The effects of advance care planning on end-of-life care: a systematic review. Palliat Med 2014;28:1000-25.

31 Davison SN, Simpson C. Hope and advance care planning in patients with end stage renal disease: qualitative interview study. BMJ 2006;333:886.

32 Horne G, Seymour J, Payne S. Maintaining integrity in the face of death: a grounded theory to explain the perspectives of people affected by lung cancer about the expression of wishes for end of life care. Int J Nurs Stud 2012;49:718-26.

33 MacPherson A, Walshe C, O'Donnell V, et al. The views of patients with severe chronic obstructive pulmonary disease on advance care planning: a qualitative study. Palliat Med 2013;27:265-72.

34 Back A, Arnold R, Tulsky J. Mastering Communication with Seriously ill Patients - Balancing Honesty with Empathy and Hope. New York: Cambridge, 2009: 158

35 Janssen DJA, Spruit MA, Schols JMGA, et al. A call for high-quality advance care planning in outpatients with severe COPD or chronic heart failure. Chest 2011;139:1081-8. 
36 Janssen DJA, Engelberg RA, Wouters EFM, et al. Advance care planning for patients with COPD: past, present and future. Patient Educ Couns 2012;86:19-24.

37 Schickedanz AD, Schillinger D, Landefeld CS, et al. A clinical framework for improving the advance care planning process: start with patients' self-identified barriers. J Am Geriatr Soc 2009;57:31-9.

38 Murray SA, Sheikh A, Thomas K. Advance care planning in primary care. BMJ 2006;333:868-9.

39 Aasmul I, Husebo BS, Sampson EL, et al. Advance care planning in nursing homes - improving the communication among patient, family, and staff: results from a cluster randomized controlled trial (Cosmos). Front Psychol 2018;9:2284.

40 Ethier J-L, Paramsothy T, You JJ, et al. Perceived barriers to goals of care discussions with patients with advanced cancer and their families in the ambulatory setting. J Palliat Care 2018;33:125-42.

41 Kelley AT, Turner J, Doolittle B. Barriers to advance care planning in end-stage renal disease: who is to blame, and what can be done? New Bioeth 2018;24:150-7.

42 Lam L, Ansari A, Baquir P, et al. Current practices, barriers and enablers for advance care planning among healthcare workers of aged care facilities in western New South Wales, Australia. Rural Remote Health 2018;18:4714.

43 Kok M, van der Werff GFM, Geerling JI, et al. Feasibility of hospital-initiated non-facilitator assisted advance care planning documentation for patients with palliative care needs. BMC Palliat Care 2018;17:79.

44 Sinclair C, Auret KA, Evans SF, et al. Advance care planning uptake among patients with severe lung disease: a randomised patient preference trial of a nurse-led, facilitated advance care planning intervention. BMJ Open 2017;7:e013415.

45 Solano JPC, da Silva AG, Soares IA, et al. Resilience and hope during advanced disease: a pilot study with metastatic colorectal cancer patients. BMC Palliat Care 2016;15:70.

46 Scott IA, Mitchell GK, J Reymond E, et al. Difficult but necessary conversations - the case for advance care planning. Med $J$ Aust 2013;199:662-6.

47 Norwegian Electronic Summary Care Record. [Web page] Norwegian Directorate of Health, 2017. Available: https://helsenorge.no/ kjernejournal [Accessed 02 Jan 2020]. 